\title{
Body Weight Gain Domain
}

National Cancer Institute

\section{Source}

National Cancer Institute. Body Weight Gain Domain. NCI Thesaurus. Code C95083.

A subject domain utilized for the submission of information encompassing and representing data, vocabulary or records related to body weight gain. 